\title{
Activation of Complement (C3) in Patients with Leprosy
}

\author{
TIN SHWE \\ Department of Clinical Tropical Medicine, \\ London School of Hygiene and Tropical Medicine \\ and \\ Burma Leprosy Service \\ and \\ R. E. PETTY \\ Department of Immunology, Institute of Child Health, London
}

\begin{abstract}
Evidence of activation of complement (C3), detected by altered mobility on immuno electrophoresis, was found in the fresh plasma of patients with lepromatous leprosy and proteinuria, with or without lepra reactions, but not in patients with other forms of leprosy. This may result from circulating antigen-antibody complexes. Such immune complexes if deposited in the capillary walls of the skin might cause erythema nodosum leprosum, and if deposited in the kidneys might cause proteinuria.
\end{abstract}

\section{Introduction}

Proteinuria is frequent in leprosy patients with a high bacterial index in skin smears, an acute erythema nodosum leprosum (ENL) reaction or reversal type of reaction, and occurs in some patients with lepromatous leprosy without skin reactions. Using the indirect fluorescent antibody technique, Wemambu et al. (1969) demonstrated deposition of immunoglobulins and complement in the skin lesions of patients with acute ENL. Also, by the fluorescent antibody technique, Tin Shwe (1971) has demonstrated the depositions of immunoglobulins and complement in renal glomeruli of 2 patients suffering from proteinuria and reversal reaction, and in one other patient with proteinuria without skin reaction.

Since such immune complexes activate complement, a study of C3 levels and immuno-electrophoretic characteristics of this complement component ( $\beta$ ic in immuno-electrophoresis nomenclature) was undertaken.

\section{Patients and Methods}

Twenty-one leprosy patients attending the Hospital for Tropical Diseases, London, were chosen for study. All the patients were classified according to the criteria of Ridley and Jopling (1966). A control group of 4 members of the staff of the Hospital for Tropical Diseases was included in the study. Specimens of 
blood from patients and controls were collected at the same time in tubes containing EDTA (ethylenediamine tetra-acetic acid). After immediate centrifugation, the fresh plasma specimens were subjected to electrophoresis on the same agar slide (barbitone buffer $\mathrm{I}=0.9, \mathrm{pH}=8.6$ ) at $+4^{\circ} \mathrm{C}$ for 1 hour (Soothill, $1967)$. Specific anti- $\beta$ ic- $\beta$ ia antisera prepared by Behringwerke were used. The slides were examined $24 \mathrm{~h}$ after electrophoresis. Two of the patients in whose serum alteration of the complement component was detected were followed at intervals for up to 4 months.

Quantitative estimation of C3 was made on the same plasma samples using Hyland immunoplates for radial diffusion. The results were expressed in $\mathrm{mg}$ per $100 \mathrm{ml}$, using the standards supplied with the plates. Proteinuria was detected by the sulphosalicylic acid test.

\section{Results}

Immuno-electrophoresis of plasma of all normal subjects used as controls revealed a single normal (uncoverted) $\beta$ ic arc (Fig. 1). This normal result was also obtained in the 4 patients with non-lepromatous leprosy and in the 7 patients

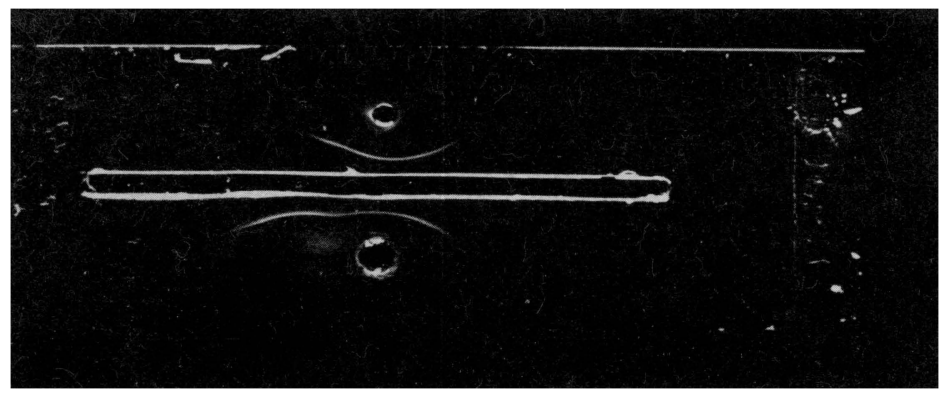

Fig. 1. Altered complement component in leprosy patient with proteinuria and reactions (above) compared with normal control (below).

with lepromatous leprosy but with no skin reactions and no proteinuria. Altered $\beta$ ic was detected in all 3 patients with recent ENL (duration less than 2 weeks) and proteinuria. The patient who had lepromatous leprosy and ENL for 18 months but no proteinuria did not show the reacted $\beta$-ic.

Of the other 6 patients with lepromatous leprosy and proteinuria, 3 showed this complement change. One had a reversal reaction, but the other 2 had no present skin reaction. Of the 3 who were negative, one had had a renal transplant for chronic renal failure and was receiving immunosuppressive treatment, one had renal failure due to amyloid, and the 3rd patient, who had had leprosy for 30 years, suffered a relapse.

Immunochemical estimation of $\mathrm{C} 3$ gave a wide range of results (Table 1). Only patient No. 25, who had had reacted $\beta$ ic, gave a low value, and he had had ENL for the shortest time, namely one week.

Two patients were followed sequentially. In patient no. 23 (LL with proteinuria and skin reactions), altered $\beta$ ic was detected 3 months prior to, and also during, the period of clinical skin reaction (ENL). The $\beta$ ic electrophoresis 
TABLE 1

Clinical and immunological features of patient groups

\begin{tabular}{|c|c|c|c|c|c|c|c|}
\hline Patient group & Serial No. & Age & Sex & Classification & Special clinical features & $\begin{array}{c}\text { Serum } \\
\text { C3 level } \\
(\mathrm{mg} / 100 \mathrm{ml})\end{array}$ & $\begin{array}{c}\text { Altered } \\
\text { complement } \\
\text { component } \\
\beta \text { ic/ßia }\end{array}$ \\
\hline \multirow[t]{4}{*}{ Controls } & 1 & 36 & M & & & 135 & - \\
\hline & 2 & 47 & M & & & 132 & - \\
\hline & 3 & 31 & $\mathrm{~F}$ & & & 110 & - \\
\hline & 4 & 20 & M & & & 145 & - \\
\hline \multirow{4}{*}{$\begin{array}{l}\text { Non-lepromatous leprosy } \\
\text { with no proteinuria }\end{array}$} & 5 & 36 & M & BB & & 148 & - \\
\hline & 6 & 20 & $\mathrm{~F}$ & BB & & 130 & - \\
\hline & 7 & 38 & $\mathrm{~F}$ & TT & & 142 & - \\
\hline & 8 & 23 & M & BT & & 105 & - \\
\hline \multirow{7}{*}{$\begin{array}{l}\text { Lepromatous leprosy, no reactions } \\
\text { and no proteinuria }\end{array}$} & 9 & 34 & M & $\mathrm{LL}$ & No ENL for $1 \mathrm{yr}$ & 80 & - \\
\hline & 10 & 47 & M & $\mathrm{LL}$ & Trophic ulcer 6 months & 170 & - \\
\hline & 11 & 39 & $\mathrm{~F}$ & $\mathrm{BL}$ & Reversal reaction 1 yr. ago & 285 & - \\
\hline & 12 & 71 & $\mathrm{~F}$ & $\mathrm{LL}$ & Trophic ulcer 8 yrs & 210 & - \\
\hline & 13 & 62 & M & $\mathrm{LL}$ & No reactions in the past & 120 & - \\
\hline & 14 & 71 & M & LL & No ENL for 3 yrs & 196 & - \\
\hline & 15 & 38 & M & LL & No reactions in the past & 185 & - \\
\hline \multicolumn{8}{|l|}{ Lepromatous leprosy with } \\
\hline chronic ENL-no proteinuria & 16 & 46 & M & LL & ENL 18 months & 150 & - \\
\hline \multirow{8}{*}{ Lepromatous leprosy and proteinuria } & 17 & 21 & $\mathrm{~F}$ & $\mathrm{BL}$ & Reversal reaction & 152 & + \\
\hline & 18 & 25 & M & LL & Hepatosplenomegaly, no skin reac & ction 210 & + \\
\hline & 19 & 31 & $\mathrm{~F}$ & $\mathrm{LL}$ & No reaction in skin & 200 & + \\
\hline & 20 & 33 & M & $\mathrm{LL}$ & Renal transplant; 6 yrs on & & \\
\hline & & & & & immunosuppressives & 85 & - \\
\hline & 21 & 52 & M & LL & $\begin{array}{l}\text { Renal failure due to amyloidosis } \\
\text { for } 9 \text { months }\end{array}$ & 160 & - \\
\hline & 22 & 64 & M & LL & Leprosy 30 yrs, in relapse & & \\
\hline & & & & & hypertension 20 yrs & 210 & - \\
\hline \multicolumn{8}{|l|}{ Lepromatous leprosy with acute } \\
\hline \multirow[t]{3}{*}{ ENL and proteinuria } & 23 & 23 & M & LL & Acute ENL 2 weeks & 220 & + \\
\hline & 24 & 47 & M & LL & Acute ENL 2 weeks & 165 & + \\
\hline & 25 & 46 & M & LL & Acute ENL 1 week & 60 & + \\
\hline
\end{tabular}


then became normal as the ENL subsided, but abnormal $\beta$ ic was again detected prior to and during the period of proteinuria which followed. Subsequently, further studies gave normal results (Fig. 2). Patient no. 24 (LL with proteinuria and skin reactions) had proteinuria and ENL at the time when electrophoretically altered $\beta$ ic was first detected. This disappeared after the ENL and proteinuria cleared up.

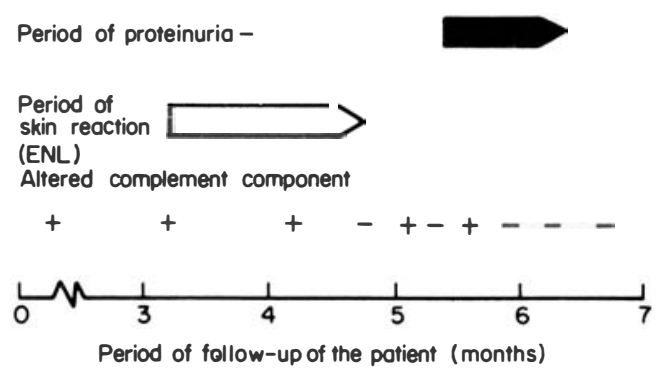

Fig. 2. Time relationships between the presence of altered complement in the plasma and the presence of skin reactions and proteinuria in patient no. 23 .

\section{Discussion}

It is believed that the low serum complement level frequently found in patients with acute glomerulonephritis is partly due to utilization of complement components in an antigen-antibody reaction. This provides indirect evidence for an immunological basis for glomerulonephritis. Electrophoretic alteration of $\beta$ ic can be induced by in vitro exposure of normal plasma to an antigen-antibody reaction (Müller-Eberhard \& Nilsson, 1960). Soothill (1965, 1967) has demonstrated that this change occurs in vivo in patients with acute glomerulonephritis (with or without low complement levels) and in some patients with the nephrotic syndrome due to proliferative glomerulonephritis, and membranous glomerulonephritis. Morse et al. (1962) and Lachmann (1963) had also demonstrated a similar phenomenon in patients with active systemic lupus erythematosus. One possible cause could be the presence of circulating soluble antigen-antibody complexes. In the present study we have demonstrated the presence of electrophoretically altered complement in all 3 of the 3 patients with a recent ENL reaction and proteinuria, and in 3 out of 6 lepromatous leprosy patients with proteinuria. The 3 patients with proteinuria, but no reacted complement, had other likely explanations for their proteinuria, namely renal transplant, amyloid, and hypertension respectively; 12 other patients without proteinuria showed no $\beta$ ic changes.

Towards the end of the first year of treatment most patients with lepromatous leprosy have ENL and some have reversal reactions. During this phase, bacterial morphology in skin smears changes from the solid to the granular form, indicative of cell death. This is presumed to be associated with antigen release and formation of complement activating antigen-antibody complexes. Clinically, this phase coincides with the development of ENL, reversal reactions, and proteinuria. The demonstration of altered $\beta$ ic at this stage in the disease is consistent with this hypothesis. Indeed the electrophoretic change may precede proteinuria or skin reaction. As recovery occurs the $\beta$ ic electrophoresis becomes normal. 
In patients with chronic lepromatous leprosy, although the acid-fast bacilli may still be present as dead granular forms, there is no more active degranulation and possibly there is no further release of antigen into the circulation. In these patients and in those patients with no bacilli in skin smears such altered complement was not detected.

This study provides evidence of complement activation, perhaps by circulating antigen-antibody complexes. It is suggested that such immune complexes when deposited in the capillary walls of the skin cause ENL, and when deposited in the glomeruli of the kidneys cause proteinuria.

\section{Acknowledgement}

We are deeply indebted to Professor J. F. Soothill, Department of Immunology, Institute of Child Health, London, Professor A. W. Woodruff, Professor of Clinical Tropical Medicine, London School of Hygiene and Tropical Medicine, and Dr D. S. Ridley, Pathologist, Hospital for Tropical Diseases, London, for all their supervision and guidance.

Our gratitude is also due to Dr W. H. Jopling, Consultant Leprologist, Hospital for Tropical Diseases, London, for his help in enabling us to carry out this study on his patients.

\section{References}

Lachmann, P. J. (1963). The formation of Bia-globulin in vivo. In Clinical Aspects of Immunology (eds Gell, P. G. H. and Coombs, R. R. A.), p. 260. Oxford: Blackwell Scientific Publications.

Morse, J. H., Müller-Eberhard, H. J. and Kunkel, H. G. (1962). Antinuclear factors and serum complement in systemic lupus ery thematosus. Bull. N.Y. Acad. Med. 38, 641.

Müller-Eberhard, H. J. and Nilsson, U. (1960). Relation of $\beta$ i-glycoprotein of human serum to the complement system. J. exp. Med. 111, 217.

Ridley, D. S. and Jopling, W. H. (1966). The classification of leprosy, according to immunity. A five group system. Int. J. Lepr. 34, 255.

Soothill, J. F. (1965). The detection of altered form of the complement component C3a ( $\beta$ ic- $\beta$ ia) in the serum of patients with various forms of glomerulonephritis. Nephron 2 , 63.

Soothill, J. F. (1967). Altered complement component C3a ( $\beta$ ic- $\beta$ ia) in patients with glomerulonephritis. Clin. exp. Immunol. 2, 83.

Tin Shwe (1971). Immune complexes in glomeruli of patients with leprosy. Lepr. Rev. 42, 282.

Wemambu, S. C. N., Turk, J. L., Waters, M. F. R. and Rees, R. J. W. (1969). Erythema nodosum leprosum, a clinical manifestation of the Arthus phenomenon. Lancet ii, 933. 